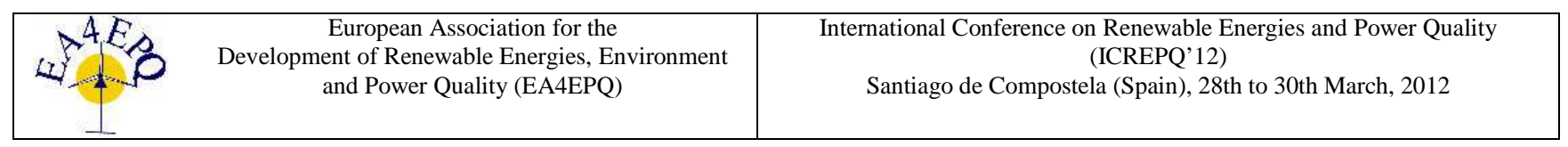

\title{
Effect of Biomass Composition on Combustion Characteristics and Energy Quality
}

\author{
I. Barmina ${ }^{1}$, A. Lickrastina ${ }^{1}$, M. Zake ${ }^{1}$, A. Arshanitsa ${ }^{2}$, V.Solodovnik, ${ }^{2}$ G. Telysheva ${ }^{2}$ \\ ${ }^{1}$ Institute of Physics, University of Latvia \\ 32 Miera Street, Salaspils-1, LV-2169 (Latvia) \\ Phone/Fax number: +371 29891137/ +371 7901214, \\ E-mail: barmina@sal.lv; mzfi@sal.lv; \\ ${ }^{2}$ Latvian State Institute of Wood Chemistry, 27 Dzerbenes Street, Riga, LV-1006, (Latvia); \\ Phone+371 29472942, fax.+371 67553063, ligno@edi.lv
}

\begin{abstract}
The main aim of this study is to provide the experimental research of the combustion characteristics for the different types of the biomass pellets during their thermo chemical conversion with estimation the correlations between the main characteristics of pelletized plant biomass and combustion characteristics. The experiments include first, the preparation of the pelletized biomass samples of different origin with certain elemental composition, heating values, moisture content, bulk and energetic density, and second, kinetic study of the combustion characteristics with local measurements of the temperature and composition of the flame reaction zone and heat production rates at different stages of the thermo chemical conversion of pelletized biomass and different air supply rates into the combustor to obtain optimal combustion conditions of plant biomass. Correlations between the main characteristics of pelletized samples and combustion/emission characteristics of pelletized biomass fuel have been derived and analyzed.
\end{abstract}

\section{Key words}

Biomass pellets, elemental composition, heating values, combustion characteristics, heat production rate.

\section{Introduction}

Because of growing interest of the clean and effective heat energy production, different renewable heat energy sources (agriculture and forestry residues) will play an important role in boiler power systems providing utilization of plant biomass and environmental protection by minimizing the impact of greenhouse carbon emissions on the climate changes. Hence, plant biomass is an attractive renewable fuel, while different plant biomass types are quite different, and the variations of biomass chemical and physical properties needs to be taken into account to assure clean and controllable heat energy production [1], [2]. The most important plant biomass characteristics for controllable combustion and heat energy production are the component and elemental composition, ash content, bulk density predetermining the energetic density of biomass as well as its behaviour at flame pyrolysis and char combustion steps. The results of previous experimental studies have shown [3]-[5] that pelletization of wheat straw and softwood biomass and their mixtures allows to increase the energetic density of biomass and control the biomass composition with stabilization of the biomass combustion characteristics, composition of polluting emission and heat production rates. In this paper, results of the kinetic study of the combustion characteristics for different types of biomass pellets are presented. The correlations between the biomass and combustion characteristics are estimated and analyzed at different air-to-fuel ratios to obtain a cleaner and more effective heat energy production, so contributing to a more complete utilization of different biomass residues for heat energy production in boiler power systems.

\section{The experimental facilities and procedures.}

The recent experimental study started with tests of the regimes of biomass pelletization providing the pelletization of different biomass types (softwood, grey alder bark, black alder bark, pine bark, willow and willow with addition of molasses). The laboratory scale pellet mill KAHL 14-175 was used for this purpose. The additive of molasses (5\% on dry mass of wood) allowed to enhance significantly the bulk density of pellets obtained (Table 1). The next step of the experiments included an ultimate and proximate analysis of the pelletized biomass samples using the standard test procedures [4], [5]. Finally, in the experimental research of the combustion characteristics of pelletized samples we used a batch-size experimental set-up composed of the updraft gasifier (1) and water-cooled sections of the combustor of diameter $\mathrm{D}=60 \mathrm{~mm}$ and length (L) up to $600 \mathrm{~mm}$ (3) (Fig.1). Biomass pellets of total mass 190 $240 \mathrm{~g}$ were loaded on the steel grate located at the bottom of the gasifier (1). Primary air was supplied below the biomass layer at a fixed rate $0,6 \mathrm{~g} / \mathrm{s}$ that provides $50 \%$ of theoretical air for the stoichiometric wood biomass burnout. Secondary swirling air was supplied to the 
bottom part of the combustor, above the biomass layer. The secondary air supply was varied from $0,6 \mathrm{~g} / \mathrm{s}$ up to 1,2 $\mathrm{g} / \mathrm{s}$ determining a swirl number of the secondary air flow $S=0,6-1,1$ and providing the formation of the central recirculation zone at the bottom part of the combustor with an enhanced mixing of the axial flow of volatiles with an air swirl. A swirl-stabilized combustion of volatiles developed downstream of the water-cooled sections of the combustor (3). The process of biomass gasification and ignition of volatiles was initiated under the stoichiometric primary air supply into biomass $(\alpha<1)$ using the additional heat energy supply into the biomass by the propane flame flow with an average heat power 1,2 kJ/s (2).

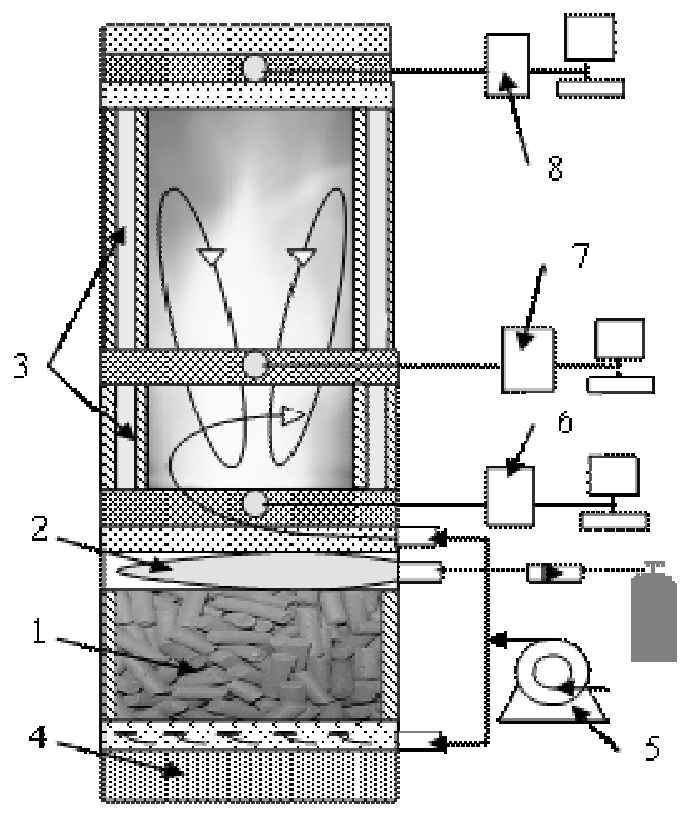

Fig.1. Principal schematic draw of the experimental set-up: 1.gasifier, charged with biomass pellets; 2 . - additional heat energy supply for initiation of the thermal conversion of biomass; 3 .water-cooled sections of the combustor; 4. - ash collection vessel; 5.- compressor for the primary and secondary air supply below and above the biomass layer; 6.- gas sampling for FTIR analysis of the flame composition; 7.- online measurements of the flame temperature; 8. - online measurements of the combustion efficiency and composition of the products.

In order to estimate the mass consumption rate for biomass pellets $(\mathrm{dm} / \mathrm{dt})$ during the thermal degradation of biomass and combustion of the volatiles, the time-dependent variations of the biomass height $(\mathrm{dL} / \mathrm{dt})$ in the gasifier were controlled using a test facility that consisting of a moving rod equipped with a pointer. The experimental study of the combustion characteristics included local online measurements of the swirling flame flow temperature, heat production rates, combustion efficiency and composition of the products at different stages of the thermal conversion of the pelletized biomass samples using $\mathrm{Pt}-\mathrm{Pt} / \mathrm{Rh}$ thermocouples, thermal sensors for the calorimetric measurements of cooling water flow, FTIR for the spectral analysis of the products close above the biomass layer, and a gas analyzer Testo 350-XL to measure the composition and temperature of the combustion products at the upper part of the combustor $(\mathrm{L} / \mathrm{D}=7)$ with estimation of the combustion efficiency at different stages of the thermo chemical conversion of the biomass pellets. The thermocouples and gas sampling probes were inserted into the flame reaction zone through the orifices of the diagnostic sections placed between the water-cooled sections of the combustor. The temperature in the flame reaction zone $(\mathrm{L} / \mathrm{D}=2,5)$, heat production rate and the composition of the products were measured online with a time interval of $1 \mathrm{sec}$.

The main characteristics of the pelletized biomass samples used in this study -softwood, grey alder bark, black alder bark, pine bark, willow and willow with addition of molasses are presented in Table I.

Table I. - Main characteristics of the biomass pellets*

\begin{tabular}{|c|c|c|c|c|c|c|}
\hline $\begin{array}{c}\text { Main } \\
\text { characteristics }\end{array}$ & 1 & 2 & 3 & 4 & 5 & 6 \\
\hline $\begin{array}{l}\text { Bulk } \\
\text { density, } \mathrm{kg} / \mathrm{m}^{3}\end{array}$ & 650 & 517 & 570 & 635 & 506 & 666 \\
\hline $\begin{array}{l}\text { Moisture } \\
\text { content, } \%\end{array}$ & 7,9 & 10,0 & 9,6 & 11,2 & 9,1 & 9,0 \\
\hline Ash content, $\%$ & 2,1 & 3,42 & 3,52 & 1,49 & 1,35 & 1,7 \\
\hline $\begin{array}{l}\text { Lower heating } \\
\text { value, } \mathrm{kWh} / \mathrm{kg} \text {, }\end{array}$ & 4,6 & 4,61 & 4,75 & 4,78 & 4,13 & 4,06 \\
\hline $\begin{array}{l}\text { Carbon content } \\
\text { DM,\% }\end{array}$ & 50,2 & 50,0 & 51,1 & 52,4 & 45,3 & 44,7 \\
\hline $\begin{array}{l}\text { Hydrogen } \\
\text { content DM,\% }\end{array}$ & 6,26 & 6,63 & 6,24 & 6,29 & 6,23 & 6,38 \\
\hline $\begin{array}{l}\text { Nitrogen } \\
\text { content DM,\% }\end{array}$ & 0,49 & 1,19 & 1,19 & 0,37 & 0,35 & 0,39 \\
\hline $\mathrm{A} / \mathrm{F}$ ratio & 6,06 & 6,56 & 6,59 & 6,55 & 5,39 & 5,39 \\
\hline
\end{tabular}

*1- softwood; 2.- grey alder bark; 3.-black alder bark; 4.- pine bark; 5.-willow; 6.-willow with molasses.

\section{Results and discussion.}

The experimental investigation of the biomass thermochemical conversion shows that the mass conversion of the biomass pellets starts after additional heat energy is injected into the upper part of the biomass layer. The primary stage of the biomass thermal conversion includes the subsequent steps of unsteady heating, drying and devolatilization determining time-dependent variations of the biomass weight loss, witch depends on the main characteristics of the biomass pellets (Fig. 2).

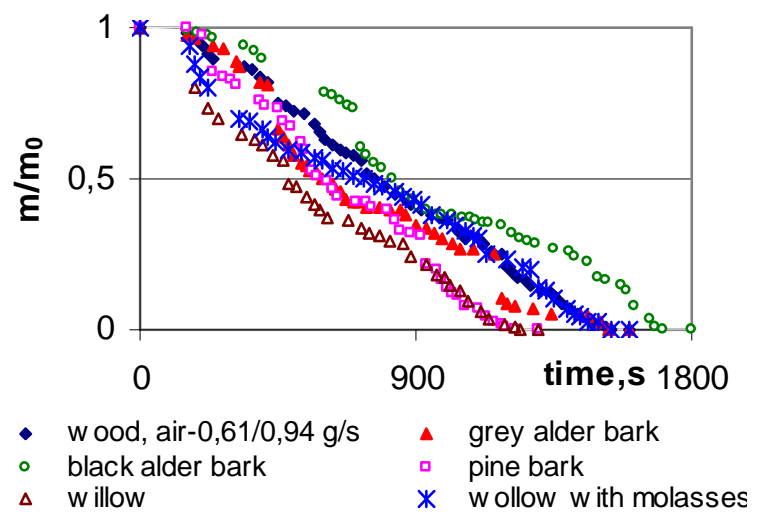

Fig.2. Time-dependent variations of the weight loss at thermochemical conversion of the different biomass samples. 
The measurements of the composition of volatiles close to the surface of the biomass by infrared FTIR spectroscopy have shown that the weight loss of the biomass pellets correlates with an intensive release of fragments of unburned hydrocarbons $\left(\mathrm{C}_{\mathrm{x}} \mathrm{H}_{\mathrm{y}}\right), \mathrm{CO}$ and $\mathrm{CO}_{2}$ (Fig.3). By analogy with the time-dependent variations of the biomass weight loss, the time-dependent variations of the composition of volatiles are influenced by the biomass type and structure (Table I).
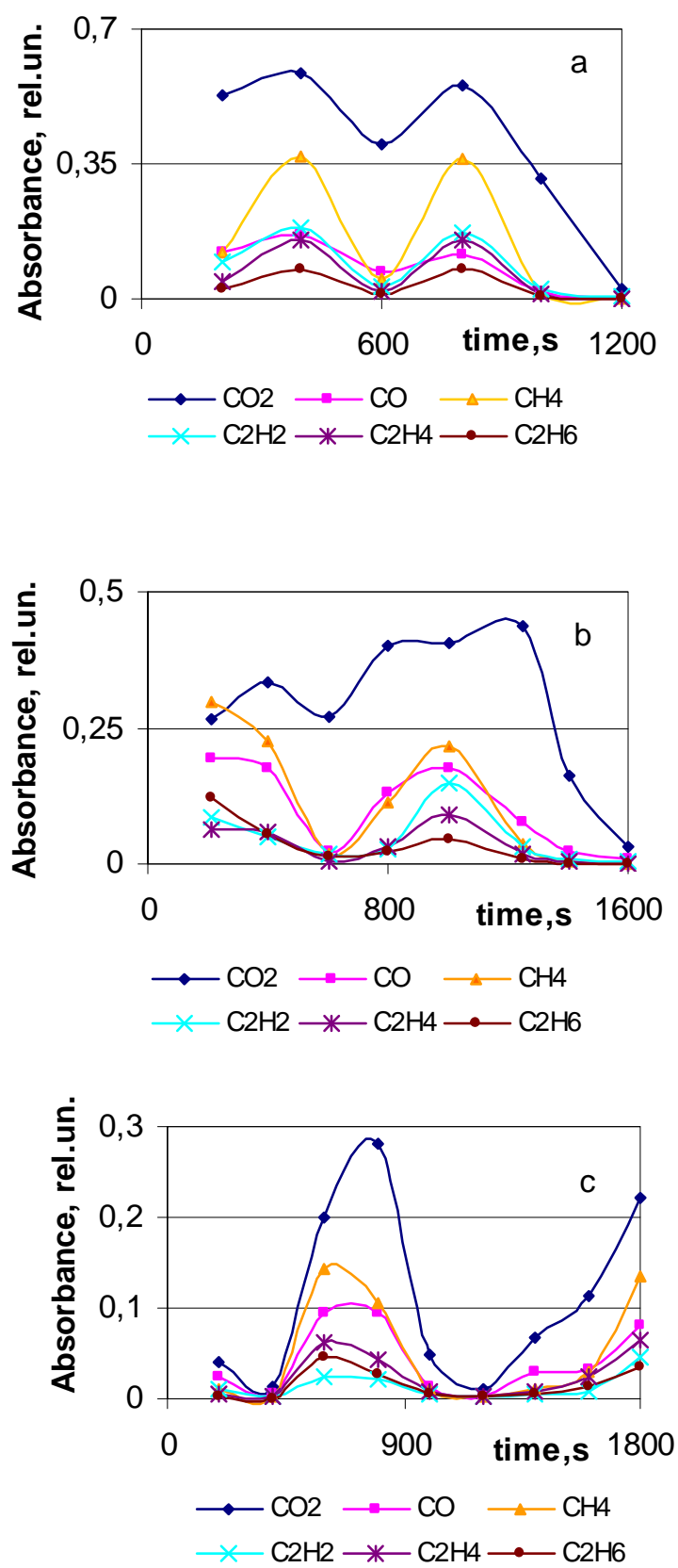

Fig. 3. Time-dependent variations of the composition of volatiles above the biomass layer during gasification of willow bark (a), pine bark (b) and grey alder (c) pellets.

As follows from Figure 3, at the fixed primary and secondary air supply rates $(0,61 / 0,78 \mathrm{~g} / \mathrm{s})$, a more intensive release of volatiles $\left(\mathrm{CH}_{4}, \mathrm{C}_{2} \mathrm{H}_{2}, \mathrm{C}_{2} \mathrm{H}_{4}, \mathrm{C}_{2} \mathrm{H}_{6}, \mathrm{CO}\right)$ at the biomass thermal decomposition can be obtained for the willow pellets (Fig. 3-a). The gasification of pine bark pellets with a higher bulk density and larger carbon content in the biomass (Table I) shows a slower devolatilization with a longer char conversion stage up to $1600 \mathrm{sec}$ (Fig.3-b). The pronounced delay of the devolatilization and char conversion stages was found for grey alder bark pellets which had higher ash content in the biomass (Fig.3-c). Once the axial flow of volatiles produced during the biomass gasification is ignited, the combustion of the volatiles develops downstream of the swirling flame flow determining the time-dependent variations of the temperature in the flame reaction zone, heat production rates and composition of the products (Figs.4 and 5).
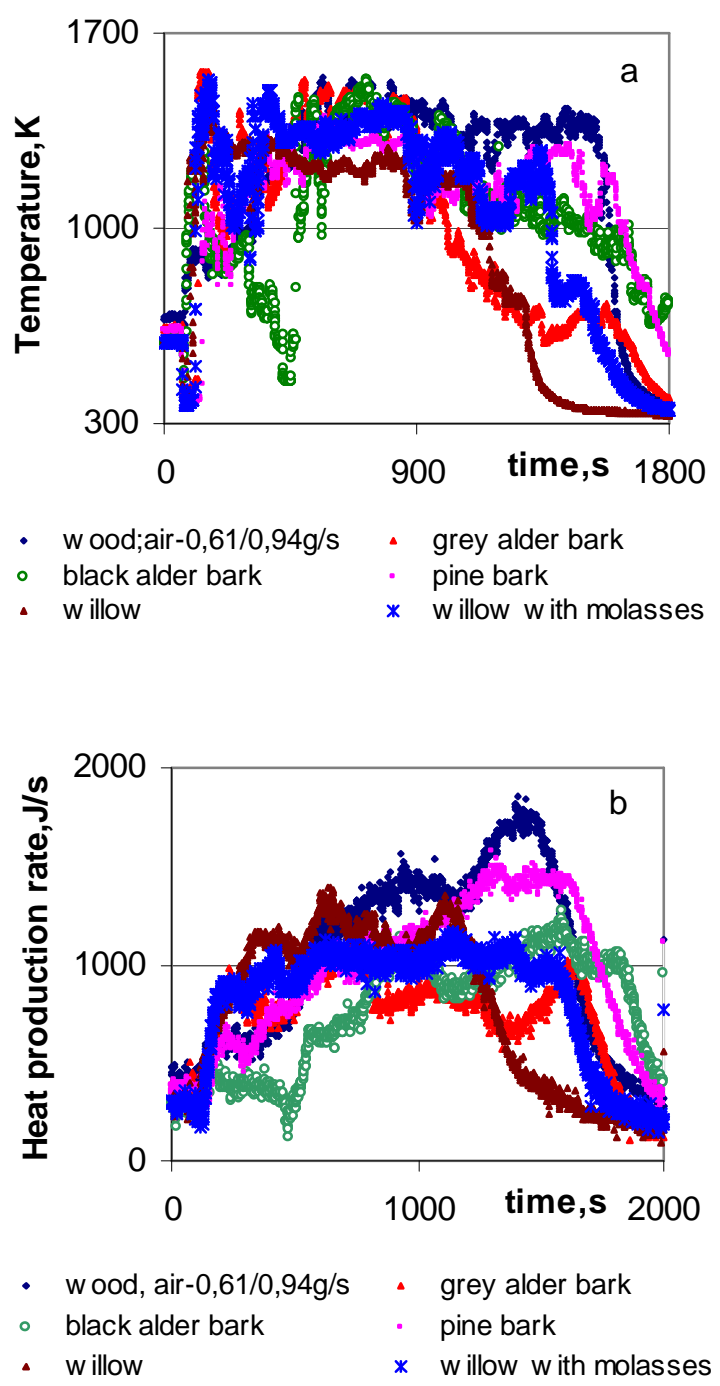

Fig. 4. Time-dependent variations of the reaction zone temperature (a) and heat production rates (b) during the thermo chemical conversion of different biomass pellets.

The complex measurements of the time-dependent variations of the temperature in the flame reaction zone, heat production rates and the composition of the products at fixed rates of primary and secondary air supply into the pilot device have revealed that, by analogy with timedependent variations of the weight loss and composition of the released volatiles (Figs.2,3), obvious differences in combustion characteristics and composition of the products at thermo-chemical conversion of biomass pellets can be obtained (Figs 4, 5). 

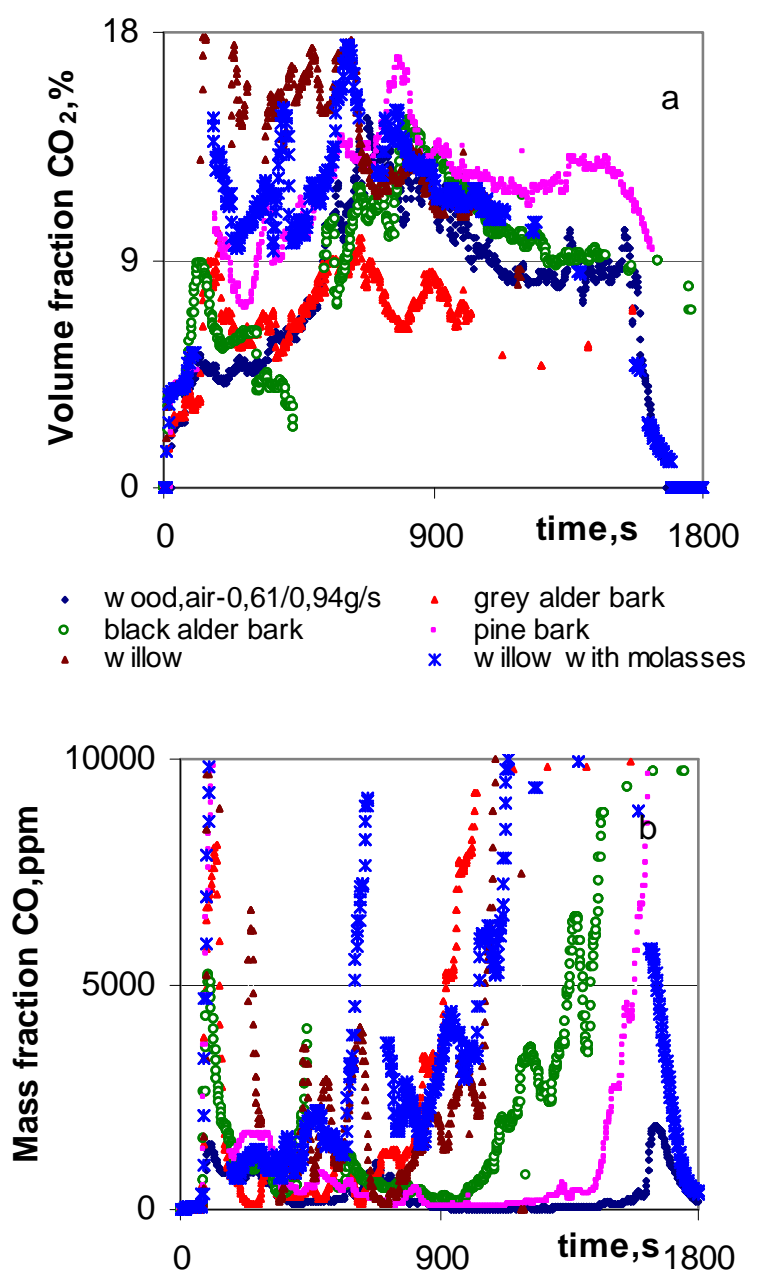

- w ood,air-0,61/0,94g/s - grey alder bark

- black alder bark - pine bark

- willow * willow with molasses

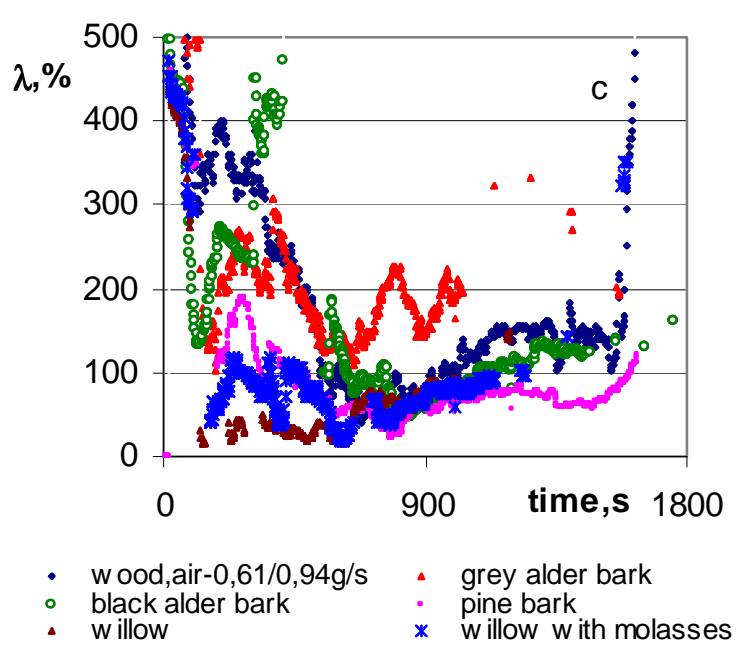

Fig. 5. Time-dependent variations of the composition of products $(a, b)$ and the air excess (c) during the thermo chemical conversion of biomass pellets.

Differences in the formation of the combustion characteristics and composition of the products for different biomass samples are observed not only during the primary stage of endothermic biomass drying and understoichiometric $(\lambda<1)$ devolatilization, but also during the combustion of volatiles developing at $\lambda>1$, and it can be approximately expressed as [6]:

$$
\begin{aligned}
& \mathrm{CH}_{1.44} \mathrm{O}_{0.6}+\lambda 1,03\left(\mathrm{O}_{2}+3,76 \mathrm{~N}_{2}\right)+\text { heat } \rightarrow \text { volatiles }(\mathrm{C}, \mathrm{CO}, \\
& \left.\mathrm{H}_{2}, \mathrm{CO}_{2}, \mathrm{C}_{\mathrm{m}} \mathrm{H}_{\mathrm{n}} \text {, etc. }\right) \rightarrow \mathrm{CO}_{2}+0.72 \mathrm{H}_{2}+(\lambda-1) \mathrm{O}_{2}+\lambda 3,87 \mathrm{~N}_{2} \\
& \text { +heat }
\end{aligned}
$$

Actually, with the fixed primary and secondary air supply rates, the combustion of volatiles develops at different ratios of the air-to-fuel $(\mathrm{A} / \mathrm{F})$ ratio, being dependent on the biomass characteristics and activation energy of the biomass gasification [7] (Table 1) and determining the time-dependent variations of the rate of the biomass weight loss and the ratio of air-to-fuel supply (Fig.2). As a result, the time-dependent variations of the air excess $(\lambda=f(t))$ in the products are observed at biomass thermochemical conversion (Fig. 5-c) with direct influence on the combustion characteristics of the biomass.

The estimation and comparison of the combustion characteristics for different biomass samples, with the fixed primary and secondary air supply rates, have shown that the process of thermo-chemical conversion of willow pellets and willow with addition of molasses develops at a relatively low average biomass consumption rate $(\mathrm{dm} / \mathrm{dt} \approx 0,14 \mathrm{~g} / \mathrm{s})$ and a high average value of the air excess $\lambda \approx 2-2,2$, determining the low average temperature of the flame reaction zone $(\mathrm{T} \approx 1200 \mathrm{~K})$ and the low average value of the produced heat $(\mathrm{Q}=7,29 \mathrm{MJ} / \mathrm{kg})$. The most intensive formation of the main product- $\mathrm{CO}_{2}$ (up to $17 \%$ ) and heat production (up to $65 \%$ ) for the willow pellets occur at the stage of volatiles burnout $-t \approx 400$ 900s (Fig. 4-b, 5-a) developing at lower activation energy of biomass gasification $(76 \mathrm{~kJ} / \mathrm{mol})$ [7], a higher weight loss of the willow pellets, which increases up to $0,23 \mathrm{~g} / \mathrm{s}$, relative high levels of the combustion efficiency (to $72 \%$ at $\mathrm{L} / \mathrm{D}=7$ ), while reduced value of the air-to-fuel ratio and equivalence ratio of the air supply $\lambda=1,24$ (Table II.).

The rapid decrease of the volume fraction of $\mathrm{CO}_{2}$ in the products with a correlating decrease of the temperature in the reaction zone and of the produced heat is observed at the final stage of char conversion of different biomass types, representing transition to endothermic heterogenous reactions between the char and main products and resulting in an increase of $\mathrm{H}_{2}$ and $\mathrm{CO}$ mass fractions in the products (Fig. 5-b) [6]:

$$
\begin{aligned}
& \mathrm{C}+\mathrm{CO}_{2}+\text { heat } \rightarrow 2 \mathrm{CO} \\
& \mathrm{C}+\mathrm{H}_{2} \mathrm{O}+\text { heat } \rightarrow \mathrm{CO}+\mathrm{H}_{2}
\end{aligned}
$$

In accordance with [7], the transition from the burnout stage of volatiles to the char conversion stage for willow pellets results in an increase of the activation energy up to $151,7 \mathrm{~kJ} / \mathrm{mol}$. Therefore, during the stage of char conversion, the weight loss rate falls, which for willow pellets decreases to about $0,13 \mathrm{~g} / \mathrm{s}$. Hence, for the fixed primary and secondary air supply rates the transition from the biomass devolatilization to the char conversion stage for willow pellets, as well as for willows with addition of molasses results in an increase of the air excess in the flame reaction zone from $\lambda \approx 1,2$ up to $\lambda=2$. This allows to suggest two main factors, which determine the increase of the mass fraction of $\mathrm{CO}$ in the products at 
the char conversion stage: first, the development of endothermic reactions $(2,3)$ and next, the increase of the air excess $(\lambda)$ at the end stage of the biomass burnout.

Table II. Variations of the weight loss and air excess ratio at the devolatilization stage for different biomass types with the fixed rates of primary and secondary air supply $(0,61 / 0,94 \mathrm{~g} / \mathrm{s})$ into the pilot device.

\begin{tabular}{|c|c|c|c|c|}
\hline $\begin{array}{c}\text { Type of biomass } \\
\text { pellets }\end{array}$ & $\mathrm{A} / \mathrm{F}_{\text {steh }}$ & $\begin{array}{c}\mathrm{dm} / \mathrm{dt}, \\
\mathrm{g} / \mathrm{s}\end{array}$ & $\begin{array}{c}\mathrm{A} / \mathrm{F}- \\
\text { sum air }\end{array}$ & $\begin{array}{c}\alpha- \\
\text { comb }\end{array}$ \\
\hline softwood & 6,06 & 0,18 & 8,60 & 1,42 \\
\hline grey alder bark & 6,58 & 0,28 & 5,62 & 0,85 \\
\hline black alder bark & 6,59 & 0,25 & 6,26 & 0,95 \\
\hline pine bark & 6,56 & 0,23 & 6,70 & 1,02 \\
\hline willow & 5,39 & 0,23 & 6,69 & 1,24 \\
\hline $\begin{array}{c}\text { willow with } \\
\text { molasses }\end{array}$ & 5,39 & 0,13 & 11,94 & 2,22 \\
\hline
\end{tabular}

The pronounced ignition delay and most longest combustion with a higher average temperature of the reaction zone $(\mathrm{T} \approx 1220-1290 \mathrm{~K})$ are observed for black alder bark pellets (Fig. 4-a), that have a higher bulk density, higher carbon content, higher heating values of biomass (Table I). At the primary stage of black alder bark devolatilization and combustion of volatiles $(t \approx 600-900 \mathrm{~s})$ the process of thermo-chemical conversion of black alder pellets is develops at the high rate of weight loss $(0,25 \mathrm{~g} / \mathrm{s})$, determining the formation of a slight excess of fuel supply in the flame reaction zone $\alpha \approx 0,95$. The peak value of $\mathrm{CO}_{2}$ in the products during this stage of thermo-chemical conversion for black alder bark pellets approaches to $15 \%$, with $75 \%$ of the combustion efficiency. Transition to the char conversion stage for black alder bark pellets is observed at $\mathrm{t}>1000 \mathrm{~K}$ with a correlating decrease of the rate of weight loss to $0,13 \mathrm{~g} / \mathrm{s}$, volume fraction of $\mathrm{CO}_{2}$ in the products falls to $9 \%$ (Fig. 5-a), while the mass fraction of $\mathrm{CO}$ in the products increases above $10000 \mathrm{ppm}$ with the air excess in the products during the char conversion $\lambda \approx 1,5-$ 1,8 (Fig. 5-b,c).

A more complete combustion of volatiles with a higher combustion efficiency is observed at the thermo-chemical conversion of pine bark pellets that develops at the average weight loss $0,19 \mathrm{~g} / \mathrm{s}$ and lower average values of the air excess ratio $\alpha \approx 1,25$. The devolatilization of pine bark and combustion of the volatiles develop at the reduced activation energy that for optimal heating conditions $(10 \mathrm{~K} / \mathrm{min})$ is about $67-71 \mathrm{~kJ} / \mathrm{mol}$ [8], determining the weight loss rate $0,23 \mathrm{~g} / \mathrm{s}$ and the formation of stoichiometric combustion conditions in the flame reaction zone (Table 2). The volume fraction of $\mathrm{CO}_{2}$ during the combustion of pine bark gradually approaches to the peak value $(15,2 \%)$, while $\mathrm{CO}$ mass fraction falls to $100 \mathrm{ppm}$ with stabilization of the combustion characteristics for pine bark pellets during the time interval from 900 up to $1500 \mathrm{sec}$, when the volume fraction of $\mathrm{CO}_{2}$ in the products slightly reduces and achieves $12 \%$ at $50-60 \mathrm{ppm}$ of $\mathrm{CO}$ mass fraction in the products. Transition to the char conversion stage for pine bark pellets is observed at $t>1400$ s, when the mass fraction of $\mathrm{CO}$ in the products starts to increase with a correlating decrease of the volume fraction of $\mathrm{CO}_{2}$, temperature of the flame reaction zone and heat production rates (Figs. 4, 5). The pronounced ignition delay at the primary stage of thermo-chemical conversion with reduced average values of the flame temperature and heat production rates during the thermochemical conversion of the biomass with a longer combustion of the volatiles (up to 1600s) is observed for softwood pellets, which under the given air supply rates develops at the average weight loss rate $0,18 \mathrm{~g} / \mathrm{s}$ and air excess ratio $\lambda \approx 1,42$.

The thermo-chemical conversion of different types of biomass in air results in quite different levels of the mass fractions of polluting nitrogen emission in the products, depending on the nitrogen content in the biomass (Table 1). As follows from Fig.6, the highest average mass fraction of $\mathrm{NO}_{\mathrm{x}}$ in the products - up to $200-350 \mathrm{ppm}$ is observed for bark alder pellets during the biomass devolatilization stage with a higher content of nitrogen in the biomass, while the minimum value of nitrogen emissions for the given combustion conditions are fixed for the softwood pellets (Fig. 6).

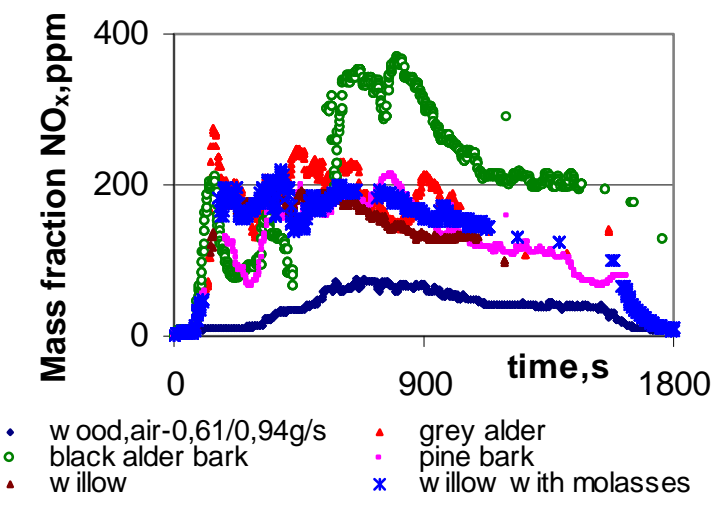

Fig. 6. Time-dependent variations of the mass fraction of $\mathrm{NO}_{\mathrm{x}}$ emission in the products at the thermo-chemical conversion of different biomass pellets.

Finally, the complex time-dependent measurements of the temperature, heat production rate and composition of the products have shown that, for fixed primary and secondary air supply rates, the large-scale timedependent variations of the combustion characteristics and composition of the products can be obtained, depending on the main characteristics of biomass, as well as on the air-to fuel supply ratio, determining the variations of the equivalence ratio of air supply and combustion conditions. Actually, the complex measurements of the weight loss, flame characteristics and composition of the products for different types of pelletized biomass have revealed a necessity to provide optimal combustion conditions for pelletized biomass to achieve the highest peak values of the volume fraction of the main product $-\mathrm{CO}_{2}$ with the higher combustion efficiency and lower air excess in the products. For softwood pellets, the optimal combustion conditions are achieved with approximately equal primary and secondary air supply rates $(0,6 \mathrm{~g} / \mathrm{s})$ when the average volume fraction of $\mathrm{CO}_{2}$ during the combustion of volatiles achieves $16-18 \%$, the combustion efficiency in the combustor at $\mathrm{L} / \mathrm{D} \approx 4-5$ achieves $80 \%$, and the air excess ratio in the reaction zone approaches to $\lambda \approx 1$, while the average air excess in the products falls to $34-45 \%$. 
The total amount of the produced heat energy downstream the combustor approaches to $8,4 \mathrm{MJ} / \mathrm{kg}$, with average temperature in the flame reaction zone $\mathrm{T} \approx 1450 \mathrm{~K}$.
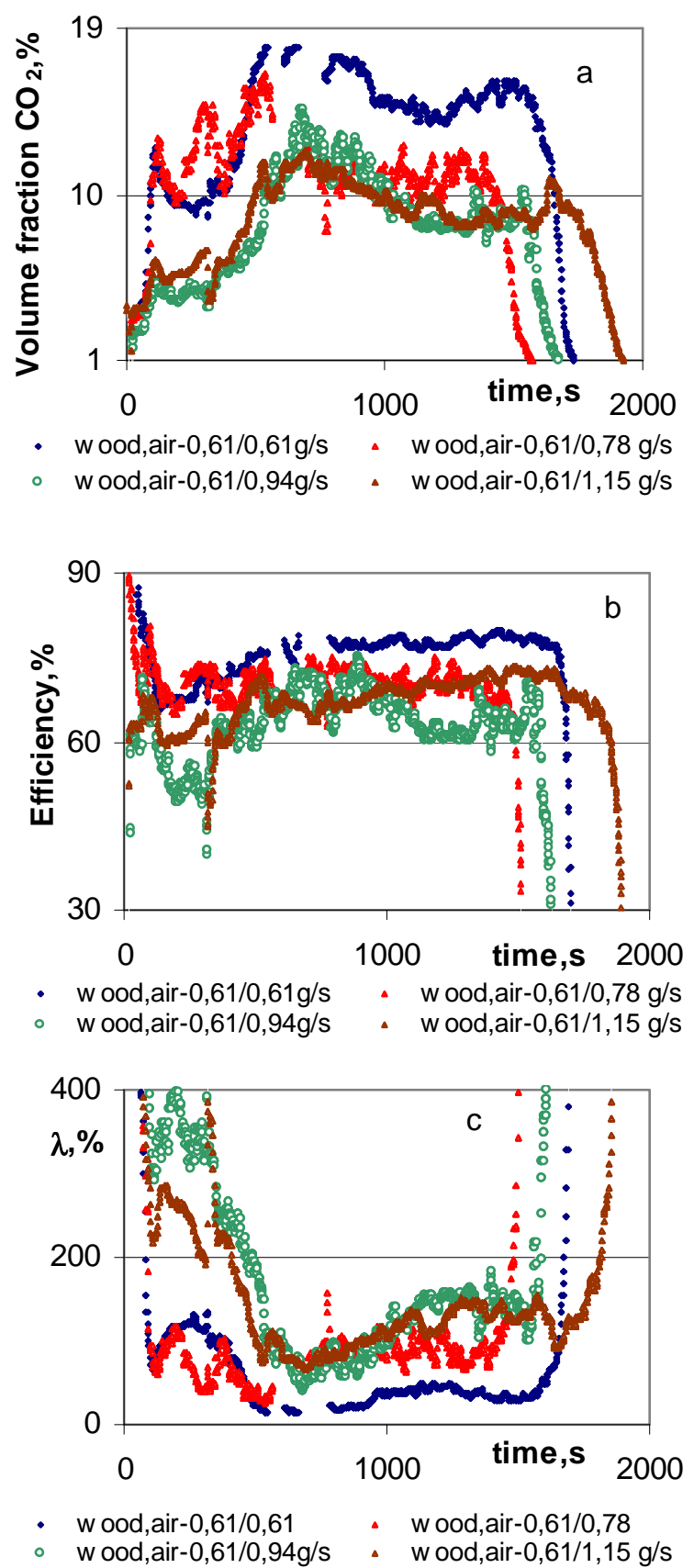

Fig. 7. Time-dependent variations of the volume fraction of $\mathrm{CO}_{2}$ emission (a), combustion efficiency (b) and air excess in the products (c) during the thermo chemical conversion of wood biomass pellets.

Increasing the secondary air supply rate into the combustor results in an increase of the air-to fuel ratio in the combustor, so decreasing the combustion efficiency of softwood pellets and the volume fraction of produced $\mathrm{CO}_{2}$ (Fig.7-a-c).

\section{Conclusion}

The obtained results testify that different types of pelletized biomass with the definite bulk density, moisture content, elemental composition and heating values could be utilized as prospective renewable carbonneutral bio fuels for the heat energy production.

The previous estimations of the stoichiometric air-to-fuel ratio which must be supplied during the thermo-chemical conversion of biomass samples and the measurements of the average weight loss rate allow predicting the combustion conditions assuring the complete combustion of volatiles.

The results of the experimental research of correlations between the main characteristics of pelletized biomass and combustion characteristics allow prognosticating the heat production rates and composition of combustion products to obtain controllable and clean process of heat energy production.

\section{Acknowledgement}

The authors would like to express their appreciation for the financial support from the European Regional Development Funding 2.1.1.1. "Support to Science and Research", Project: Nr.2010/0241/2DP/2.1.1.1.0/10/APIA/VIAA/006 and financial support of Latvian Grant V7705.

\section{References}

[1] Demirbas A., Potential applications of renewable energy sources, biomass combustion problems in boiler power systems and combustion related environmental issues, in: Progress in Energy and Combustion Science, 2005, Vol. 31, pp. 171-192.

[2] Dietenberger M., Update for Combustion Properties of Wood Components, in: Fire and Materials, 2002, Vol. 26, pp. 255-267.

[3] Arshanitsa A., Barmina I., Andersone A., Telysheva G., Zake M., Processing and Complex Research of the Main Characteristics of Pelletized Lignocellulosic Materials for Clean and Effective Energy Production, International, in: Scientific Colloquium Modelling for Material Processing, Riga, September 16-17, 2010, pp. 151-156.

[4] Arshanitsa A., Barmina I., Telysheva G., Dizhbite T., Andersone A., Zake M., Grants I., The composition and fuel characteristics of non-hydrolyzed residues from wheat straw ethanol production, in: Proc. 8th Intern. Sci. Conference "Engineering for Rural Development", Jelgava, 2009, pp.105111.

[5] Arshanitsa A., Telysheva G., Dizhbite T., Barmina I., Zake M., Pelletizing process of non-hydrolyzed residues from wheat straw ethanol production and fuel characteristics of pellets obtained, in: Proceedings of 3-rd International Symposium on Energy from Biomass and Waste, Venice, 2010, pp.6.

[6] T. Nussbaumer, Combustion and co-combustion of biomass: fundamentals, technologies and primary measures for emission reduction, Energy\&Fuels, 2003, 17, pp. 1510-1521.

[7] M. J. Prins, Thermodynamic analysis of biomass gasification and torrefication, Ph.D thesis, Technical University of Eindhoven, 2006, pp.167.

[8] H.J.M. Belderok, Experimental investigation and modeling of the pyrolysis of biomass, Master thesis, Technical University of Eindhoven, 2007, pp. 133. 